\title{
Not all febrile critical illness with rash is infective: Drug reaction may be a mimic
}

\author{
Ashok Kumar Pannu, M. B. Adarsh, Navneet Sharma \\ Department of Internal Medicine, Postgraduate Institute of Medical Education and Research, Chandigarh, India
}

\section{Abstract}

We report a case of ciprofloxacin-related drug rash with eosinophilia and systemic symptoms (DRESS) which was initially diagnosed and managed on the line of tropical fever. Later, a diagnosis of definite case of DRESS was made according to the RegiSCAR scoring system and the patient was managed with the removal of ciprofloxacin along with steroids. DRESS is a great masquerader. The diagnosis should be highly suspected in the presence of fever, skin rash, liver involvement, and hypereosinophilia.

Keywords: Drug rash with eosinophilia and systemic symptoms, LEMDS, multi-organ dysfunction, tropical fever

\section{INTRODUCTION}

Tropical fevers are defined as infections that are prevalent in or are unique to tropical and subtropical regions. They occur in different parts of the Indian subcontinent throughout the year, especially in rainy and postrainy season. These fevers include leptospirosis, enteric fever, malaria, dengue, scrub typhus (can be remembered as mnemonic LEMDS) and some other fevers. They have overlapping clinical presentation, multi-system involvement, require Intensive Care Unit (ICU) care, and are associated with high morbidity and mortality. Clinical picture of these diseases is usually so overlapping that it is not always possible to achieve differential diagnosis in emergency and ICU settings. A "syndromic approach" is usually followed for diagnosis and treatment of these infections. The major five clinical syndromes are undifferentiated fever, fever with rash or thrombocytopenia, fever with acute respiratory distress syndrome, fever with encephalopathy, and fever with multi-organ dysfunction syndrome (MODS). ${ }^{[1]}$

Here, we report a case presented in rainy season with fever, rash, and MODS, which was initially investigated and managed as tropical fever, but later, a diagnosis of drug rash with eosinophilia and systemic symptoms (DRESS) was established.

\begin{tabular}{|l|l|}
\hline \multicolumn{2}{|c|}{ Access this article online } \\
\hline Quick Response Code: & Website: \\
\hline & www.ijccm.org \\
\hline & \\
\hline
\end{tabular}

\section{Case Report}

A 32-year-old woman presented with fever, skin rash, dyspnea, jaundice, and decreased urine output in the emergency department on July 5, 2015.

The patient had been well until 10 days before admission when low-grade fever developed. Two days after the onset of fever, she went to a local practitioner and was prescribed oral ciprofloxacin. Next day, she became afebrile but she developed maculopapular skin rash with itching, which started on the bilateral upper limbs and progressed to involve whole body in the next 24-48 h [Figure 1]. Simultaneously, she also noticed swelling over face and hands. Three days after the onset of rash, fever reappeared. This time, it was high grade and associated with chills. The same day, she developed shortness of breath which progressed to dyspnea at rest within 2 days with dry cough and orthopnea. Three days before admission, the patient developed jaundice with

Address for correspondence: Dr. Ashok Kumar Pannu, Department of Internal Medicine, $4^{\text {th }}$ Floor, F Block, Postgraduate Institute of Medical Education and Research, Chandigarh - 160 012, India. E-mail: gawaribacchi@gmail.com

This is an open access article distributed under the terms of the Creative Commons Attribution-NonCommercial-ShareAlike 3.0 License, which allows others to remix, tweak, and build upon the work non-commercially, as long as the author is credited and the new creations are licensed under the identical terms.

For reprints contact: reprints@medknow.com 
high-colored urine without cholestatic symptoms, and her urine output reduced to $500 \mathrm{ml} /$ day.

The patient had no known allergies. She had not noted any insect bites. She was a homemaker and had no history of recent travel. She was a vegetarian and had no addictions. Her menstrual cycles were normal, and she was married with two children without abortions.

On examination, she was conscious and oriented with blood pressure of $110 / 56 \mathrm{~mm}$ of $\mathrm{Hg}$, pulse rate of $110 / \mathrm{min}$, respiratory rate of $26 / \mathrm{min}$, temperature of $39^{\circ} \mathrm{C}$, and oxygen saturation $96 \%$ on oxygen supplementation with $\mathrm{FiO}_{2} 0.5$ and flow $121 / \mathrm{min}$. She had icterus, facial and bilateral hand swelling, as well as bilateral symmetrical pitting pedal edema. Oral mucous membrane was also edematous. There were nontender discrete lymph nodes in the bilateral cervical regions; the largest was on the right side and measured $2 \mathrm{~cm}$ in diameter. Skin rash was diffuse maculopapular involving whole body ( $>90 \%$ body surface area), nonblanching with occasional pustules. No eschar was seen. A presumptive diagnosis of tropical fever with rash and multi-organ involvement was made, and the patient was

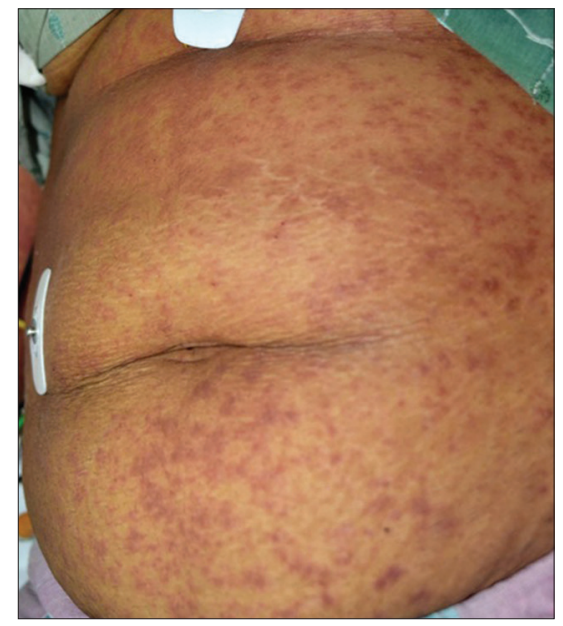

Figure 1: Maculopapular drug rash empirically started of ceftriaxone and doxycycline. Laboratory investigation showed hemoglobin of $9.1 \mathrm{~g} / \mathrm{dl}$; total leukocyte count of $21.2 \times 10^{9} / 1$ with $48 \%$ neutrophils, $15 \%$ lymphocytes, $1 \%$ monocytes, and 36\% eosinophils (absolute eosinophil count - $\left.7.610^{9} / 1\right)$; platelet counts of $281 \times 10^{9} / 1$; creatinine level of $2.4 \mathrm{mg} / \mathrm{dl}$; total bilirubin of $7.3 \mathrm{mg} / \mathrm{dl}$ with conjugated fraction of $6.7 \mathrm{mg} / \mathrm{dl}$; aspartate aminotransferase (AST), alanine aminotransferase (ALT), and alkaline phosphatase (ALP) of 1048 IU/1, 965 IU/1, and 332 IU/1, respectively; international normalized ratio of 1.8; and serum albumin of $2.0 \mathrm{~g} / \mathrm{dl}$. Cardiac troponin I and creatine kinase-MB were normal. Serum lipase and amylase levels were $381 \mathrm{U} / 1$ and $375 \mathrm{U} / 1$, respectively. Serum lactate dehydrogenase level was 1032 U/1. A peripheral blood smear showed more than $5 \%$ atypical lymphocytes. Chest X-ray showed bilateral mild pleural effusion and ultrasonography abdomen revealed hepatosplenomegaly with moderate ascites.

Rapid kit test and peripheral smear for malaria, serological tests for dengue (NS1 Ag, IgM and IgG antibody), leptospirosis (IgM antibody), scrub typhus (IgM antibody), widal, viral hepatitis (hepatitis A virus IgM, hepatitis E virus IgM, hepatitis B surface antigen, anti-hepatitis C virus antibody), HIV ELISA, and antinuclear antibody gave negative results. Urine analysis did not show eosinophils, red cells, or albumin. Blood and urine cultures were sterile. A skin biopsy was done which was suggestive of drug rash with thinned out epidermis, flattening of rete pegs, spongiosis and vacuolization of dermoepidermal junction, presence of apoptotic keratinocytes, and dermis showing perivascular lymphocytic inflammatory infiltrates. A diagnosis of DRESS secondary to ciprofloxacin with hepatic, hematological, renal, and pulmonary involvement was made. Antibiotics were stopped and she was started on prednisolone $1 \mathrm{mg} / \mathrm{kg} /$ day, following which she had a rapid improvement in systemic symptoms and eosinophilia. At discharge on July 17 , absolute eosinophil count was $0.35 \times 10^{9} / 1$, serum creatinine $0.43 \mathrm{mg} / \mathrm{dl}$, total bilirubin $2.0 \mathrm{mg} / \mathrm{dl}$, and AST, ALT, and ALP 166, 335, and 200, IU/1 respectively. On outpatient department follow-up, the patient had flare of skin rash on

Table 1: RegiSCAR diagnosis score for drug rash with eosinophilia and systemic symptoms

\begin{tabular}{|c|c|c|c|c|}
\hline & \multicolumn{4}{|c|}{ Scores } \\
\hline & -1 & 0 & 1 & 2 \\
\hline Fever $\geq 38^{\circ} \mathrm{C}$ & $\mathrm{No} / \mathrm{U}$ & Yes & - & - \\
\hline Enlarged lymph nodes $(\geq 2$ sites, $\geq 1 \mathrm{~cm})$ & - & $\mathrm{No} / \mathrm{U}$ & Yes & - \\
\hline Eosinophilia $\left(\mu \mathrm{l}^{-1}\right.$ or $\left.\%\right)$ & - & $\mathrm{No} / \mathrm{U}$ & $700-1499$ or $10 \%-19.9 \%$ & $\geq 1500$ or $\geq 20 \%$ \\
\hline Skin rash & - & $\mathrm{No} / \mathrm{U}$ & - & - \\
\hline Rash extent $\geq 50 \%$ (body surface) & - & No & Yes & - \\
\hline Skin rash suggesting DRESS & No & $\mathrm{U}$ & Yes & - \\
\hline Biopsy suggesting DRESS & No & $\mathrm{Yes} / \mathrm{U}$ & - & - \\
\hline Internal organ involvement & - & $\mathrm{No} / \mathrm{U}$ & One & Two or more \\
\hline Resolution in $\geq 15$ days & $\mathrm{No} / \mathrm{U}$ & Yes & - & - \\
\hline $\begin{array}{l}\text { At least three biological investigations done and } \\
\text { negative to exclude other alternative diagnosis }\end{array}$ & - & $\mathrm{No} / \mathrm{U}$ & Yes & - \\
\hline
\end{tabular}

Final score $<2$ : No; 2-3: Possible; 4-5: Probable; $>$ 5: Definite diagnosis. DRESS: Drug rash with eosinophilia and systemic symptoms; $\mathrm{U}$ : Unknown/unclassifiable 
steroid withdrawal. Rash completely resolved by the $3^{\text {rd }}$ month after restarting steroid.

\section{Discussion}

DRESS is a life-threatening, idiosyncratic drug reaction. Common culprit drugs are aromatic anticonvulsants, antidepressants, allopurinol, antimicrobials, sulfonamides and sulfones, and nonsteroidal anti-inflammatory drugs. Antimicrobial commonly involved are abacavir, nevirapine, minocycline, linezolid, doxycycline, nitrofurantoin, metronidazole, piperacillin-tazobactam, and ceftriaxone. ${ }^{[2]}$

Fever $>38^{\circ} \mathrm{C}$, malaise, and rash are the presenting features. Rash is symmetric, confluent, pruritic, maculopapular and affects face, upper trunk, upper extremities first, followed by lower extremities. Facial edema, particularly periorbital, is typical. Mucosa may be involved, usually only one site without erosion. ${ }^{[3]}$

Hepatic involvement occurs in 50\%-70\% cases, which presents as tender hepatomegaly, transaminitis, granulomatous hepatitis, and even fulminant hepatic failure. Renal involvement is seen in $10 \%-30 \%$ patients and manifests as hematuria, mild proteinuria, interstitial nephritis, or acute renal failure. Hematological abnormalities occur as eosinophilia, atypical lymphocytosis, and lymphadenopathy. Lung (Interstitial pneumonitis, pleural effusion), heart (eosinophilic myocarditis, pericarditis), pancreas (pancreatitis), muscle (myositis), and other organs may be involved. ${ }^{[3-5]}$

The RegiSCAR scoring system is most commonly used criteria to diagnose DRESS [Table 1]. ${ }^{[6]}$ Our case was diagnosed as a definite case of DRESS with score 8 (fever $>38^{\circ} \mathrm{C}$, lymphadenopathy, eosinophilia $36 \%$, typical rash, multi-organ involvement with excluding other potential causes and resolution in $>15$ days).

Prompt diagnosis and withdrawal of the offending drug are important. High-dose corticosteroids (0.5-1 mg/kg/day) are the cornerstone of therapy. A dramatic improvement is seen soon after corticosteroids; however, it should be slowly tapered while the function of affected organs is closely monitored to minimize recurrences. ${ }^{[7]}$

\section{Conclusion}

Not all fevers with rash and MODS are tropical fever. DRESS is a great masquerader. Early identification and removal of offending drug along with steroids can do wonder.

\section{Financial support and sponsorship}

Nil.

\section{Conflicts of interest}

There are no conflicts of interest.

\section{ReFEREnCES}

1. Singhi S, Chaudhary D, Varghese GM, Bhalla A, Karthi N, Kalantri S, et al. Tropical fevers: Management guidelines. Indian J Crit Care Med 2014; 18:62-9.

2. Gentile I, Talamo M, Borgia G. Is the drug-induced hypersensitivity syndrome (DIHS) due to human herpesvirus 6 infection or to allergy-mediated viral reactivation? Report of a case and literature review. BMC Infect Dis 2010;10:49.

3. Bocquet H, Bagot M, Roujeau JC. Drug-induced pseudolymphoma and drug hypersensitivity syndrome (drug rash with eosinophilia and systemic symptoms: DRESS). Semin Cutan Med Surg 1996;15:250-7.

4. Kano Y, Ishida T, Hirahara K, Shiohara T. Visceral involvements and long-term sequelae in drug-induced hypersensitivity syndrome. Med Clin North Am 2010;94:743-59, xi.

5. Kardaun SH, Sidoroff A, Valeyrie-Allanore L, Halevy S, Davidovici BB, Mockenhaupt M, et al. Variability in the clinical pattern of cutaneous side-effects of drugs with systemic symptoms: Does a DRESS syndrome really exist? Br J Dermatol 2007;156:609-11.

6. Ben m'rad M, Leclerc-Mercier S, Blanche P, Franck N, Rozenberg F, Fulla Y, et al. Drug-induced hypersensitivity syndrome: Clinical and biologic disease patterns in 24 patients. Medicine (Baltimore) 2009;88:131-40

7. Tas S, Simonart T. Management of drug rash with eosinophilia and systemic symptoms (DRESS syndrome): An update. Dermatology 2003;206:353-6. 